\title{
CURRENT RESEARCH PROBLEMS IN ADMINISTRATIVE STUDIES IN POLAND AND GERMANY
}

\author{
RENATA KUSIAK-WINTER*
}

This publication is the result of a Polish-German scientific conference entitled "Current research problems in Administrative Studies in Poland and in Germany". The conference took place on October $21^{\text {st }}$ and $22^{\text {nd }}, 2016$ in Wrockaw and was organised as part of the Lower Silesian Meeting of Researchers in Administrative Studies. The event was attended by researchers, academic teachers and a large group of students (including $\mathrm{PhD}$ students) of the Faculty of Law, Administration and Economics of the University of Wrocław and the Meissen University of Applied Administrative Sciences, Centre for Continuing Education (Hochschule Meissen und Fortbildungszentrum). The thematic scope of the conference was focused on a set of civilizational challenges and problems faced by public administration entities in both countries.

After a period of systemic transformation and after Poland's accession to the European Union the country has gone through a period of organising international meetings and conferences. The objective of these conferences was to facilitate the mutual learning of legal systems coupled with an identification of similarities and differences between particular national models of public administration. The comparative studies hitherto conducted indicate clearly that the structural and functional layout of the Polish public administration system has a number of connections and shared features with its German counterpart - despite the fact that there are, unfortunately, significant differences in the levels of public spending in the two countries. Currently, the preferred object of comparative studies between the two countries is problem-solving and modes of addressing the challenges of modernity as well as presenting recommended changes in legislation or improvements in the methods of public governance. This is the current object of study for the scholars who deal with administrative studies, and, at the same time, a determinant of teaching and training curricula at universities and other tertiary education institutions.

DOI: $10.1515 /$ wrlae-2015-0045

${ }^{*} \mathrm{PhD}$ in Law, Assistant Professor at the Institute of Administrative Sciences, Faculty of Law, Administration and Economics, University of Wrocław; renata.kusiakwinter@uwr.edu.pl 
Although the history of cooperation between experts in administrative law from Saxony and Lower Silesia is not a very long one, it is rich in its content. The collaboration was launched in May 2015 during a Polish-Czech-German conference organised at the Faculty of Law, Administration and Economy of the University of Wroclaw. The conference's lead theme was "European territorial cooperation for the development of the border areas of Poland, Czech Republic and Germany." Later that year, in August, students from the Faculty of Law, Administration and Economy took part in an International Summer Course in Meissen where, in addition to inspiring discussions with politicians and representatives of ministries of Saxony, the focus was also on integrating the community of students and $\mathrm{PhD}$ students from Germany, Poland and the Ukraine.

The scope of subjects discussed during the last conference resulted in a selection of articles for this volume and was developed after consultations with research and teaching staff of both universities. This volume, entitled "Current research problems in Administrative Studies in Poland and in Germany", reflects both the object of research and elements of the curriculum for future civil servants applied at both universities. The articles constitute a perfect point of departure for the preparation of future joint research projects in the field. Furthermore, from a practical angle the volume facilitates research aimed at finding mutually applicable solutions to existing problems.

A characteristic feature of most of the articles presented in this volume is the fact that they address concrete thematic issues from the perspective of both Poland and Germany as analysed by scholars from Wrocław and Meissen. The resulting dual viewpoint on the same issues shows the complexity of the determinants which impact administration and its functioning in both countries.

In the first part of this edition of WRLAE we present some questions concerning comparative studies in administrative law, with particular emphasis on the links between the public administrations of Poland and Germany (Renata Kusiak-Winter, Magdalena Tabernacka, Barbara Zyzda). According to the authors, the essence and importance of the contemporary comparative studies in administration must be perceived in the broad context of their cognitive objectives, the quest for new directions for the development of administrative comparative studies, and the necessity to build bridges and communication channels, learn from others and inspire the undertaking of new forms of structuring administrative phenomena.

Further subjects in the volume are presented in parallel by researchers from Meissen and Wrocław. Frank Nolden and Jerzy Korczak describe the current challenges and expectations facing the system of education and management of human resources in public administration. The authors quote recently acquired statistical data from Saxony and Lower Silesia. While the German perspective is dominated by unfavourable demographic developments in the country, in Poland the quality of HR management in Lower Silesia is determined by a low quality of the relevant administrative regulations passed down by the central lawmaker. The resulting disadvantageous HR situation of this region of Poland is no different than that of the country's other regions. 
The next subject presented in the volume is that of social assistance, in particular the relationship between citizens and the social assistance administration. In their articles, Matthias Thum and Dominika Cendrowicz discuss some elements of the system of social assistance with its fundamental principles of equal access and social justice. The German article sees highly detailed and complicated regulations as a major drawback of the welfare system, whereas the Polish article, to the contrary, presents the extensive system of legal regulations as a guarantee for the fulfilment of social needs, and a guarantee for the correct shaping of the state's social assistance policy.

Further tandem articles by Polish and German authors focus on selected aspects of financial management and financial law: Isabelle Jänchen and Przemysław Pest analyse financial equalization instruments by taking two different perspectives: a broad one and a narrow one. Isabelle Jänchen adopts a broad European perspective and looks at the causes of the lack of comparable metrics for the assessment of integrated budget management across different European countries. Przemysław Pest, in turn, focuses on a local and regional perspective on equalization of revenues of Local Self-Government Units (LSGUs) in Poland.

Another question regarding public finance addressed by the articles is the taxation of public entities in Poland and in Germany. Fritz Lang, Andrzej Huchla and Pierre Frotscher analyse the relevant legal regulations. German lawmakers have introduced separate tax obligations for public entities. In turn, Polish acts of tax law do not even contain the general category of public sector entities. Despite that difference it turns out that, due to Poland's EU membership, it is of primary importance to facilitate unrestrained competition and avoid preferential tax treatment of public entities - a requirement which is not always respected in both countries.

The volume's last subject presented in the Polish-German tandem mode is the problem of communication between bureaucracy and citizens as well as entrepreneurs, seen through the prism of information asymmetries. Claudia Lubk perceives the asymmetries as a major source of a negative image of bureaucracy in Germany, and goes on to indicate a number of possible strategies to remedy the problem. In turn, Agnieszka ChrisiduBudnik and Justyna Przedańska offer a critical analysis of the Polish public procurement system in which the lawmakers did not take into account the phenomenon of information asymmetry in the communication between bureaucracy and entrepreneurs.

The articles by Polish and German researchers presented in this volume and focused on the same or similar subjects indicate clearly that despite the distinctness of the two legal, economic, financial and demographic systems, and despite different organisational cultures which determine the structures and functions of public administration, the results of the scientific research presented here have one common denominator. That denominator is the quest for objective truth, as well as posing inquisitive and challenging questions concerning the functioning of public administration, its social reception and the desired directions for its future development. 
I would like to express my heartfelt thanks to the Authors of the articles in this volume, in particular to our friends from the Meissen University: thank you for your important and inspiring contributions to the final shape of this edition of the Wroclaw Review of Law, Administration and Economics. Let me also express my sincere hope that the results of the research presented here will constitute an incentive for further in-depth research initiatives and new joint research and teaching initiatives being taken up by our Universities. 